\title{
Developing a new tariff plan of a telecommunications company taking into account subscribers' and investors' preferences
}

\section{Tatiana K. Bogdanova}

Associate Professor, Department of Business Analytics

National Research University Higher School of Economics

Address: 20, Myasnitskaya Street, Moscow, 101000, Russian Federation

E-mail: tanbog@hse.ru

\section{Dmitry Y. Neklyudov}

Data Analyst, Department of Big Data, StandardProject Ltd.;

Senior Lecturer, Department of Business Analytics

National Research University Higher School of Economics

Address: 20, Myasnitskaya Street, Moscow, 101000, Russian Federation

E-mail:dyuneklyudov@hse.ru

\section{Olga M. Uvarova}

Leading Expert, Laboratory of Enterprise Competitiveness Problems Analysis

Senior Lecturer, Department of Business Analytics

National Research University Higher School of Economics

Address: 20, Myasnitskaya Street, Moscow, 101000, Russian Federation

E-mail: ouvarova@hse.ru

\section{Abstract}

The market of telecommunication services and its evolution has an essential impact on development strategies of all industries. In recent times, we observe a tendency for the operators' business to shift from providing communications services to supplying integrated ICT services. A positive trend line of market growth is predicted for the coming five years. However, the problem of keeping and even expanding the subscriber base is an ongoing task of all telecom companies. One of the possible solutions to this problem is developing a rational tariff policy, which may take into consideration not only the interests of the company and its investors, but also the subscribers' preferences. One of the main components of the tariff policy is developing new tariff plans, which meet the afore-mentioned requirements.

In the paper, a new concept of tariff plan development is proposed. It is based on identifying stable groups of existing tariff plans and subscribers' preferences that are non-linearly related with tariff plan characteristics. The proposed method is based on the concept of client lifetime value (CLV) that characterizes discounted profit received from a customer during all the time he consumes services from the company. This approach gives us an opportunity to build-up a CLV forming model, relying on subscriber's consumption of mobile services and price characteristics of tariff plans. This seems quite important in the conditions of volatility of the high tech market and intensive changes in patterns of subscribers' consumption of services.

Within the proposed concept, an info-logical model for developing and evaluating a new tariff plan is developed. The model is based on the synthesis of neural networks and genetic algorithm. The proposed model allows us to make assessment of combinations of tariff plans' price characteristics 
created by telecom company specialists, and to determine an optimal combination representing local or global maximum of CLV in the given time interval. This may be done for each subscriber's consumption profile and for the given period.

The approach gives us an opportunity to choose a tariff plan (from existing and newly created tariffs) for every subscriber cluster, which satisfies subscribers and investor preferences while providing maximum company profit.

Key words: telecommunications company, telecommunications service market, tariff plan, subscribers' preferences, subscriber consumption profile, client life-time value, intelligent methods of data analysis, clustering, modeling, tariff policy, neural network, genetic algorithm.

Citation: Bogdanova T.K., Neklyudov D.Y., Uvarova O.M. (2018) Developing a new tariff plan of a telecommunications company taking into account subscribers' and investors' preferences.

Business Informatics, no. 1 (43), pp. 39-49. DOI: 10.17323/1998-0663.2018.1.39.49.

\section{Introduction}

$\mathrm{I}$ $\mathrm{n}$ the opinion of most analysts, the market of telecommunications services is one of the most technological and competitive markets in Russia. Its development has an extremely high impact on the economy of the whole country. Most telecom operators have come to the conclusion that the future belongs to wireless networks. The technology of $5 \mathrm{G}$ networks is still under development: approval of the standards is planned not earlier than in 2019, and availability of commercial applications - only in 2020. However, telecom operators are actively promoting this technology because they understand that in the future it may provide essential competitive advantages.

According to the TMT Consulting analytical agency, after the long recession the growth rate of telecommunication companies' income has shown positive trends over the last two years [1]. Such accelerated rates became possible because of the growth of the mobile communications segment, which was caused by several reasons: refusal to engage in price competition, avoiding unlimited tariffs, as well as high dynamics of profit from additional services in the segment of corporate clients. For these reasons, in Q3 2017 all the "big three" operators for the first time showed the positive growth of average revenue per user (ARPU) [2], which is the most important metric for the commercial activity of a telecommunications company (Figure 1).

At the same time, the trend of 2016 towards reducing inter-operator services and fixed phone communications is continuing to exert a negative influence on market dynamics. We see this in declining popularity of fixed communications services and falling ruble profit from rendering inter-operator services to foreign operators (Figure 2).

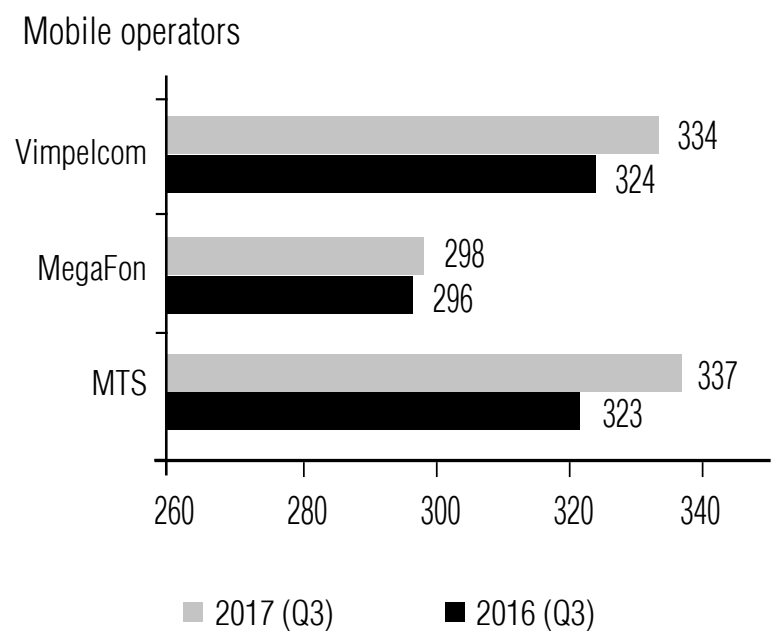

Fig. 1. ARPU of the federal mobile operators Russian Federation (rubles) 


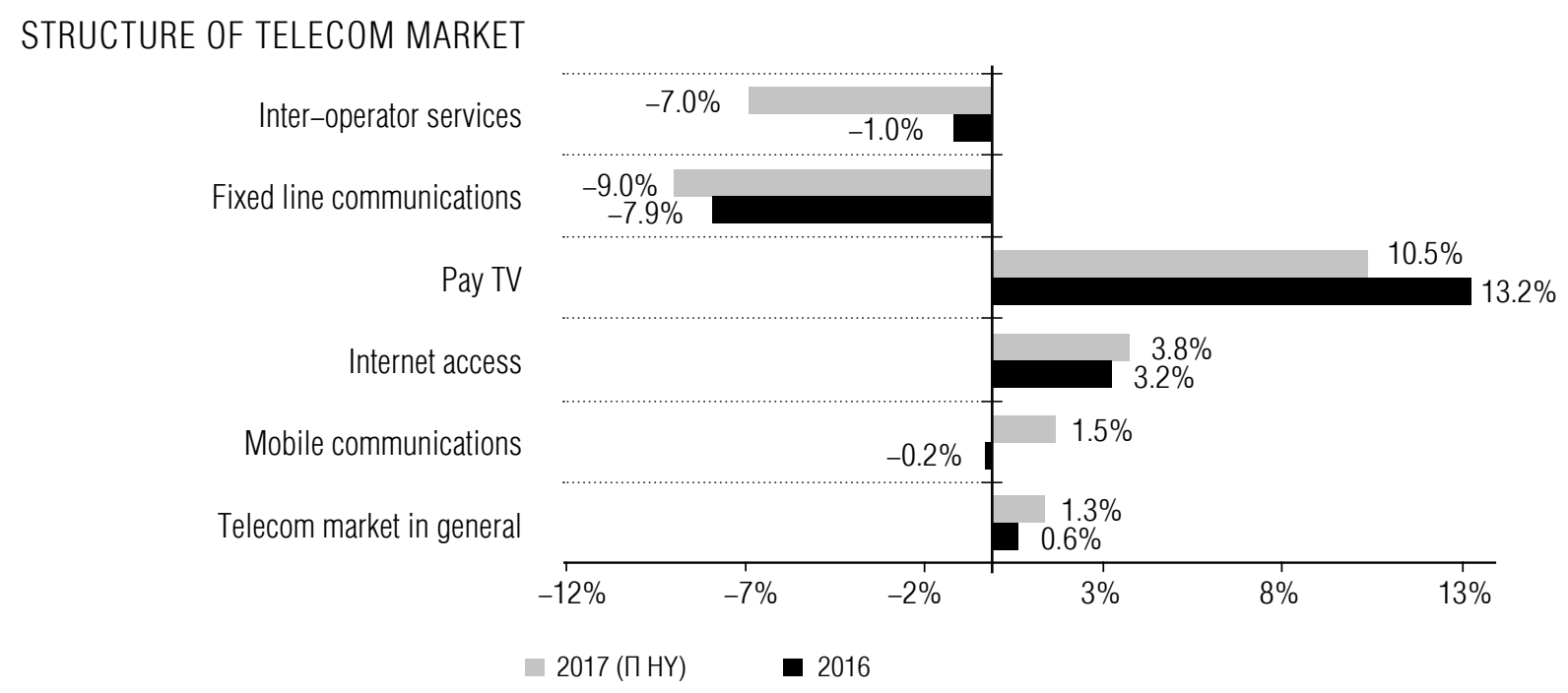

Fig. 2. Trend lines of the various segments of the telecommunication service market

According to preliminary data provided by TMT Consulting [1], subscriber base growth is continuing: in 2016 it was only $0.6 \%$, but in 2017 the number of mobile communications subscribers increased by $1.7 \%$ to 260 million. For all the mobile operators, there is a tendency of transformation from communications providers into suppliers of integrated ICT services including system integration, services of data centers and cloud computing among others. Service packages allow subscribers to pay less for each of the components and provide growth of profit per user, as well as increasing subscribers' loyalty to the operator. The tactics for keeping subscribers, as well as expanding the client base and offering them more attractive (in comparison with competitors) conditions on a permanent basis (instead of short-term marketing actions) strengthens price rivalry on the telecommunications services market. Forming a rational regional tariff policy of a telecommunications company, taking into consideration consumption profiles of subscriber clusters and investors' preferences is the main task for any company to gain competitive advantages. For that reason, it is an timely task to develop tariff plans which, taking into consideration subscribers' preferences, will not only earn profits for a telecommunications company but also will contribute to keeping subscribers, i.e. retaining the subscriber base [3].

The process of developing a new tariff plan is very labor consuming. As a rule, it isn't formalized; rather it depends on experience and intuition of the developer, who also has some information about competitors' novelties. So any even partial automation of this process provides an opportunity not only to reduce the development time, but also to receive an instrument that helps to assess quite objectively the target audience for which the new tariff plan can be attractive. Therefore, it is an opportunity to reduce the company's expenses related to new tariff plan development and implementation.

\section{Clustering of subscribers}

It is argued in [3] that shaping the tariff policy of a telecommunication company requires taking into consideration not only interests of certain subscribers, but also interests of subscriber groups having similar consumption characteristics and profiles. Additionally, it is necessary to consider investors' 
requirements regarding time intervals during which their profit should be maximized. A distinguishing feature of this method is that forming the subscriber profile is based only on quantitative characteristics of the traffic used, as well as shares reflecting the internal structure of telecom services consumption. Subscribers' socio-demographic characteristics are not taken into consideration. This method relies on the fact that the subscriber base is not a range of individual customers with certain socio-demographic characteristics, but a set of SIM (subscriber identification module) cards, any of which is characterized by a certain set of parameters. This allows us to avoid possible mistakes of clustering using subscribers' socio-demographic characteristics, because each person can have several SIM cards and, on the other hand, a registered user and a real customer may be different persons.

Information about consumer characteristics of each subscriber, which is available in any telecommunications company, contains factors which often are closely interrelated. Thus, when describing consumer profiles of the subscribers it is reasonable to make clustering using not information stored in a telecommunications company's data base, but independent latent variables (factors) which can be received using factor analysis or the method of principal components.

The procedure of forming subscriber clusters with similar consumption characteristics includes two steps. In the first step, relying on subscribers' initial characteristics (duration of voice calls within the same cellular network or using competitor networks, volume of SMS messages, traffic volume, etc.) and with the use of factor analysis, independent behavioral factors are identified. In the second step subscribers' consumer profiles, which represent a basis for subscriber clustering, are identified.

Each telecommunications company tries to maximize the profit it earns through its tar- iff policy. As the main metric for determining profitability of a telecommunication company, in the paper [3] a client life-time value (CLV) is proposed. This indicator shows discounted profit received from the client during all the time he consumes the company's services. On the one hand, CLV characterizes profitability of a telecommunication company (i.e. represents the company's interests), on the other hand, the indicator reflects subscriber preferences that are characterized by outflow of customers. Subscriber outflow is the main point showing the loyalty of the company's subscribers, because it is directly related with subscribers' level of satisfaction with the company's activity.

\section{Clustering of tariff plans}

The characteristic of subscriber preferences is the price of those tariff plans which are used by any company subscriber. However calculating the real price of a tariff plan is a tough task because it includes many subtleties of the mobile services offering, for example, bonuses, discounts, as well as different services and packages modifying the tariff plan price. Furthermore, tariff plans are permanently corrected by the company. From time to time modifications are issued, and new tariff plans are developed. Therefore, there are a number of tariff plans offered by a telecommunications company, which may exist simultaneously. However, not all of them are available by open access for subscribers.

It is proposed in [3] that instead of the declared prices of tariff plans selected by subscribers, it is reasonable to use the ratio of total charges from every subscriber to the total traffic consumed by the client. Therefore, it is possible to get the real price of each product consumed by all the subscribers for any tariff plan. Like in the case of subscriber clusters formation, developing tariff plan groups is related to the problem of multi-collinearity of primary financial characteristics of a tariff plan. Thus, 
for identifying tariff plan groups with similar characteristics it is recommended to perform clustering relying on latent independent variables (factors) determined using the principal components method.

The procedure of tariff plan clustering includes two steps. In the first step, independent pricing factors are determined, using factor analysis based on tariff plans initial characteristics (cost of one minute of voice traffic within the mobile network or using competitors' networks, cost of SMS messages, cost of Internet traffic, etc.). In the second step, stable tariff plan groups (clusters) are identified with the help of clustering methods.

Execution of this model gives us an opportunity to form a few permanent tariff plan clusters with significant differences in pricing characteristics.

Using different tariff plans has impact on clients' satisfaction and on the company's profitability. Therefore, CLV should be different for the same subscriber when using different tariff plans. In order to determine a tariff plan that is optimal for a certain subscriber (and that, in turn, increases mutual benefits from the collaboration between a mobile company and the subscriber), it is necessary that the subscriber use each of the tariff plans within the same conditions. However, for a certain subscriber such a practice seems impossible.

That is why, instead of considering how different tariff plans are used by a certain subscriber, it is possible to analyze consumption profiles that characterize a subscriber group with similar behavioral features. This allows us to compare different tariff plan using subscriber groups with similar consumption characteristics. From the point of view of the mobile company and its subscribers, a tariff plan that provides maximal CLV for each subscriber cluster is optimal, because its characteristics take into account subscriber preferences, while the company earns maximum profit.

\section{Developing a new tariff plan}

All of the foregoing considerations concern already existing tariff plans. However, one of the main streams in a telecommunications company's tariff policy is developing new tariff plans. The reasons that force the company to develop new tariff plans are serious rivalry on the telecommunications market, the high-tech nature of the market, as well as active changing of subscribers' consumption paradigms relating to services on offer.

The concept for formation of new tariff plans of a telecommunications company proposed by the authors is based on identifying stable groups of existing tariff plans, as well as subscriber preferences that are non-linearly related with the tariff plan characteristics. This allows us to create a CLV forming model that relies on consumption of mobile services by subscriber and tariff plan pricing characteristics. This concept is based on subscriber value (CLV) analysis according to subscriber consumption profile, tariff plan characteristics and planning period. The planning period characterizes investors' preferences because when setting it the investor determines the period within which he intends to get a return on his investments.

For implementation of a new tariff plan, it is necessary to have a formalized understanding of subscriber preferences regarding tariff plans. In other words, it is necessary to know the price of a single traffic unit and average traffic per subscriber for each subscriber consumption profile and for each existing tariff plan. Using regression analysis [4-6] and a pre-defined set of a tariff plan characteristics, it is possible to develop a model for predicting CLV. The model would determine discounted profit gained from the subscribers of a certain consumption profile, during all time they consume the company's services [7]. The CLV indicator also characterizes subscriber satisfaction regarding relations with the company, because it allows us to account for the 
share of subscribers outflows during the analyzing time period [8]. The developed regression model also provides useful information for a telecommunications company about the tariff plan characteristics that are most important for each subscriber cluster.

Using tariff plan groups for regression model based CLV forecasting would give results that are more precise. However, if the total number of tariff plan groups is relatively small, it is preferable to develop a model relying on all the company's existing tariff plans.

Assessment of a new tariff plan is performed relying on CLV calculation for each subscriber cluster according to the formula:

$$
C L V_{i}^{\prime}=\sum_{e=1}^{E_{i}} w_{e i} \cdot x_{e i},
$$

where $C L V_{i}^{\prime}$ - projected CLV of the $i$-th subscriber cluster, $i=1, \ldots, I$;

$w_{e i}$ - coefficient of multiple linear regression, based on the sample of existing tariff plans in the $i$-th subscriber cluster, $e=1, \ldots, E_{i}, i=1$, ..., I;

$x_{e i}$ - regressor showing one of the tariff plan's pricing characteristics that is valuable for the $i$-th subscriber cluster, $e=1, \ldots, E_{i}, i=1, \ldots, I$;

$E_{i}$ - number of valuable regressors of the $i$-th subscriber cluster, $i=1, \ldots, I$;

$I$ - total number of subscriber clusters.

If financial characteristics are unrestricted, description of pricing preferences using regression functions do not allow us to develop a new tariff plan. A new tariff plan includes hardly formalized parameters, and it makes the task of automated formation quite difficult. The number of pricing characteristics that describe a tariff plan can be large. At the same time, subscriber attitudes to pricing characteristics are variable depending on their level. This probably will be expressed by a non-linear relationship between CLV and the tariff plan's pricing characteristics. Solution of this task is possible using a neural network $[9,10]$ because this method automatically allows us to consider nonlinear relations between parameters. Mathematical principles incorporated in the algorithm are similar to the working of the human brain, and this feature provides greater flexibility of data analysis. Another considerable advantage of the neural network is the universality of its application for processing data of different types. Therefore, application of this method allows us to develop a neural network based model which may help to discover interrelations between tariff plan financial characteristics and CLV for all subscriber clusters.

There are two main disadvantages of neural networks. The first is the high probability of retraining the algorithm, because of considering too precise characteristics of nonlinear relationships. This problem is especially relevant for small datasets. For formation of the neural network, information is used that characterizes tariff plans for all planning sub-periods and for all consumer profiles of subscribers (i.e. the sample is quite small), so the problem of re-training is timely.

The second disadvantage is complexity of understanding and logical analysis of the identified relations, even if the number of neurons is equal to three. Taking into consideration that the number of neurons depends on the number of parameters and, as a rule, is much more than three, description of the neural network and analysis of its parameters are practically impossible.

As a result of the second disadvantage for the task "creating an optimal tariff plan for each subscriber cluster and for all the periods, using neural network," it is impossible to calculate combinations of financial characteristics which are estimated by the neural network as CLV maximum. However, for this task this disadvantage of the neural network algorithm is not so important, because the purpose of the research is not to explain the influence of financial characteristics on CLV, but to determine the optimal group of tariff plans for subscribers, with subsequent forming of tariff policy. 
It is possible to get an optimal combination of financial characteristics applying an heuristic algorithm that is able to select such a combination of financial parameters, which will be considered by a trained neural network as CLV maximum for given subscriber clusters during the given planning period. The task may be solved using any heuristic algorithm, including genetic algorithm that at present is quite popular.

The most valuable advantages of genetic algorithms include the possibility of global extremum search, universality in working with indicators being optimized, as well operating speed.

A genetic algorithm is a mechanism of evolutionary calculations (or heuristic optimization) which is developed by analogy with the natural selection process created by the nature. The main mechanism of genetic algorithms includes several steps.

In the first step, a set of genes described by the set of chromosomes (for example, the tariff plan characteristics) is formed. All the characteristics are defined randomly.

In the second step, it is necessary to assess each gene (for example, it is possible to analyze tariff plan characteristics with the help of a trained neural network) and to get a quantitative measure of this gene's quality (it is usually called the "gene's fitness").

In the third step, a new set of genes (or a new generation) based on the previous gene generation is formed. Each gene has its own probability to put its chromosomes into genes of the next generation. This probability depends on the results of assessment of this gene's quality. The formation of each descendant of a new generation is based on two predecessors of the previous generation. Descendants' genes are crossed (usually it is said that crossover is available), and a new unique chromosome set of a new gene, composed by the predecessors' elements, is created.

In the fourth step, formed gene descendants in casual chromosomes are stochastically changed (or mutated). It is the step which gives new information included into genes.

All the steps from the second to the fourth are processed iteratively, while a pre-defined stopping criterion will be reached [11].

There are many variants to make the algorithm more complicated. They allow us to search the optimum faster and to increase the probability of finding the global extremum. However, the general principle of the algorithm remains the same.

The general procedure for forming a new tariff plan is as follows. First of all, relying on determined earlier sets of subscriber clusters and tariff plans, as well as identified investor preferences, a CLV calculation is performed. This is done for each tariff plan cluster and each subscriber cluster, and for all the periods of tariff policy planning. Then formation and training of a neural network for CLV prediction is executed. It is done for each subscriber cluster according to the planning period and tariff plan financial characteristics. Then, using a trained neural model, existing and possible new tariff plans are assessed. The tariff plans characteristics are entered into the trained model. Then with the help of the genetic algorithm we heuristically select the optimal combination of tariff plan characteristics. This may become a basis for forming a new tariff plan of the mobile company.

\section{Approval of the method of developing a new tariff plan for a telecommunication company on the real data}

Approval of the proposed method of developing a new tariff plan for a telecommunications company was executed using IBM SPSS Modeler 19.0 on an informational base containing $2,356,753$ observations of 232,451 unique subscribers in Moscow and the Moscow Region, which is $2.5 \%$ of the subscriber base of the company. This sample represents monthly collected data for the period from 1 January 2011 to 31 December 2014. 
The total number of variables characterizing subscriber consumption which were used for identifying subscriber profiles equal 103. To determine profiles of subscriber consumption (subscriber clusters) 34 characteristics were used. They represent main traffic channels (voice traffic, Internet traffic, SMS traffic) and are described by the following set of properties:

$\downarrow$ direction of communications: incoming or outgoing traffic;

$\downarrow$ subscriber geography: local area connection, national roaming, international roaming;

v call geography: local area call, call in Russia, international call;

$\checkmark$ receiving operator: call in the same mobile network, call using competitor networks, call to stationary phone numbers.

Each characteristic may be expressed either in natural units, or by a ratio.

As the primary characteristics are multi-collinear, relying on them, using principal components method, 14 independent latent variables (factors) were identified. On the basis of these 14 factors and self-organized Kohonen cards [12] subscriber clustering was done. It allowed us to discover 24 profiles of different subscriber behavior, with significant differences ( $p$-value $<0.01$ ) regarding both the 14 factors and 34 source variables.

For identifying tariff plan groups with similar financial characteristics, 14 indicators of subscriber traffic tariffing were used. They include: cost of one megabyte of Internet traffic, cost of one SMS, cost of one minute of local and international calls, etc. The total number of tariff plans considered was 198. For identifying permanent groups of tariff plans relying on these financial characteristics, in the paper [3] it is recommended to use independent latent variables (factors). Using the method of principal components, five independent factors characterizing a tariff plan were identified:

$\diamond$ factor $1-$ the need for extensive cheap communications within Moscow; factor 2 - the need for extensive cheap communications and roaming within Russia and CIS;

$\diamond$ factor 3 - the need for international communications and roaming (except CIS countries);

$\diamond$ factor $4-$ cost of SMS messages;

$\diamond$ factor $5-$ cost of access to Internet.

Relying on these independent factors and using Kohonen maps [12] clustering of the 83 most popular tariff plans from 198 existing ones was executed. As a result, 11 permanent groups of tariff plans were discovered. These groups differ considerably from each other and have similar internal cluster characteristics.

There are the following tariff plans groups that were identified:

$\diamond$ unlimited and packaged tariff plans;

$\checkmark$ packaged tariff plans that includes direct city area phone number;

$\downarrow$ per-minute tariff plans with a common rate;

$\checkmark$ per-minute tariff plans targeted to CIS;

$\diamond$ Internet tariff plans;

$\downarrow$ Internet tariff plans with possibility of voice calls, targeted on regions;

$\uparrow$ per-second tariff plans;

$\checkmark$ tariff plans targeted to Moscow city;

$\downarrow$ two groups of specific non-popular tariff plans.

Analysis of the determined clusters according to major characteristics (Internet traffic, voice traffic, CLV, average subscriber lifetime) allowed us to draw the following conclusions. Subscribers of the 11-th cluster consume only Internet traffic: 6.8 GB per month in average, which is significantly more than in any other cluster. Meanwhile, voice traffic consumption is 10 minutes, CLV is 730 rubles and average subscriber lifetime is 20.5 months. Subscribers from clusters with numbers $4,6,8,10,15,18$ and 21 have high voice traffic consumption (from 338 till $601 \mathrm{~min}$ - 
utes) and very low Internet traffic consumption (from 74 till $200 \mathrm{MB}$ ). Subscribers from clusters 22,23 and 24 are characterized by very low consumption of telecommunications services (less than 72 minutes of voice traffic and less than $124 \mathrm{MB}$ of Internet traffic). Subscribers from clusters 1, 2 and 3 have the greatest need of telecommunications services consumption: average voice traffic consumption is from 739 to 909 minutes, and Internet traffic consumption - from 329 to 462 MB. As parameters for clustering, we used the characteristics of telecommunications services consumption, while all the clusters also significantly differ from each other by CLV.

Calculations of CLV for different planning horizons according to identified subscriber clusters and tariff plan groups showed that Z-values of average CLV for different tariff plans groups are very different for the same subscriber cluster than is characterized by certain type of consumption. For example, for the first subscriber cluster Z-value of average CLV varies from -0.4 to 6.3 , for the 3 -rd cluster - from -0.4 to 5.9 , for the 4 -th - from -0.4 to 5.4 . It should be noted that there are groups of tariff plans which have permanently low Z-value of average CLV, regardless the subscriber cluster. For example, for the 9-th group of tariff plans the confines are from -0.8 to 0.4 , and for the 10 -th group - from -0.8 to -0.1 .

Table 1 shows us that the same group of tariff plans provides maximum profit for the majority of the subscriber clusters, regardless of the specified period. However, there are clusters where maximum profit is gained with the use of different groups of tariff plans (e.g. clusters 1 and 20).

Thus, for the first subscriber cluster and planning periods of one to three years, the maximum value of CLV is reached using the 3-rd tariff plan group. However, for the four years planning period the 1 st tariff plan group is preferable, as the most profitable. For the 20 -th subscriber cluster and planning period of one year, the maximum value of CLV is reached using the first tariff plan group, and for other periods - using the 9-th tariff plan group. The results partially confirm the advanced hypothesis that for different planning periods and for each subscriber cluster the most profitable tariff plans groups may be different.

For tariff plans groups with numbers 2, 4, 6, 8,10 and 11 for all the subscriber clusters the maximal CLV is not greater than average value for any of the planning periods. Hence, it is possible to draw the conclusion that the mobile operator should consider replacing these tariff plans with other ones which, on the one hand, may bring maximum profit in any planning period and, on the other hand - take into account subscriber preferences.

The model of CLV estimation depending on financial characteristics of tariff plans was realized in practice using IBM SPSS Modeler 19.0 software. The model included the following stages. First of all, $5 \%$ of the most unpopular tariff plans for each subscriber cluster were excluded from subsequent consideration. Then, for each subscriber cluster and each planning period, a neural network was developed for CLV forecasting taking into consideration tariff plan financial characteristics, as well as subscriber and investor preferences regarding new tariff plans. Then this neural network was used by a genetic algorithm developed as a Windows application on $\mathrm{C} \#$ language, to discover optimal combination of tariff plan financial characteristics that provide maximum value of CLV.

By analyzing the results received, it is possible to make a justifiable decision regarding reasonability of using a certain tariff plan for each subscriber cluster. This allows management to focus marketing activities on popularization of these tariff plans among subscribers of the appropriate subscriber clusters. 
Relations between subscriber clusters, tariff plan groups

Table 1. and $Z$-values of the average CLV for different periods of profit calculation

\begin{tabular}{|c|c|c|c|c|c|c|c|c|}
\hline \multirow{3}{*}{$\begin{array}{l}\text { Subscriber } \\
\text { clusters }\end{array}$} & \multicolumn{8}{|c|}{ Profit calculation period } \\
\hline & \multicolumn{2}{|r|}{1 year } & \multicolumn{2}{|r|}{2 years } & \multicolumn{2}{|r|}{3 years } & \multicolumn{2}{|r|}{4 years } \\
\hline & $\mathrm{TP}^{1}$ & $\begin{array}{l}\text { Z-values of } \\
\text { average CLV }\end{array}$ & TP1 & $\begin{array}{l}\text { Z-values of } \\
\text { average CLV }\end{array}$ & TP1 & $\begin{array}{l}\text { Z-values of } \\
\text { average CLV }\end{array}$ & TP1 & $\begin{array}{l}\text { Z-values of } \\
\text { average CLV }\end{array}$ \\
\hline 1 & 3 & 1.6 & 3 & 2.5 & 3 & 3.0 & 1 & 3.2 \\
\hline 2 & 1 & 0.6 & 1 & 0.9 & 1 & 1.2 & 1 & 1.4 \\
\hline 3 & 1 & 0.7 & 1 & 1.1 & 1 & 1.4 & 1 & 1.7 \\
\hline 4 & 1 & 0.9 & 1 & 1.3 & 1 & 1.5 & 1 & 1.7 \\
\hline 5 & 1 & 0.1 & 1 & 0.3 & 1 & 0.4 & 1 & 0.6 \\
\hline 6 & 1 & 0.1 & 1 & 0.4 & 1 & 0.5 & 1 & 0.5 \\
\hline 7 & 1 & 0.1 & 1 & 0.4 & 1 & 0.6 & 1 & 0.7 \\
\hline 8 & 1 & 0.6 & 1 & 1.0 & 1 & 1.5 & 1 & 1.8 \\
\hline 9 & 1 & -0.1 & 1 & 0.1 & 1 & 0.3 & 1 & 0.4 \\
\hline 10 & 1 & -0.2 & 1 & -0.0 & 1 & 0.1 & 1 & 0.2 \\
\hline 11 & 7 & 0.3 & 7 & 0.6 & 7 & 0.7 & 7 & 0.8 \\
\hline 12 & 5 & -0.1 & 5 & 0.1 & 5 & 0.2 & 5 & 0.2 \\
\hline 13 & 1 & -0.1 & 1 & 0.1 & 1 & 0.2 & 1 & 0.3 \\
\hline 14 & 5 & -0.2 & 5 & -0.0 & 5 & 0.1 & 5 & 0.1 \\
\hline 15 & 1 & 0.0 & 1 & 0.2 & 1 & 0.4 & 1 & 0.5 \\
\hline 16 & 1 & -0.4 & 1 & -0.3 & 1 & -0.3 & 1 & -0.3 \\
\hline 17 & 5 & -0.3 & 5 & -0.2 & 5 & -0.1 & 5 & -0.0 \\
\hline 18 & 1 & -0.1 & 1 & 0.1 & 1 & 0.2 & 1 & 0.4 \\
\hline 19 & 1 & -0.2 & 1 & -0.1 & 1 & 0.0 & 1 & 0.1 \\
\hline 20 & 1 & -0.3 & 9 & -0.2 & 9 & -0.1 & 9 & -0.1 \\
\hline 21 & 1 & -0.3 & 1 & -0.2 & 1 & -0.1 & 1 & 0.0 \\
\hline 22 & 1 & -0.6 & 1 & -0.5 & 1 & -0.5 & 1 & -0.4 \\
\hline 23 & 5 & -0.7 & 5 & -0.6 & 5 & -0.6 & 5 & -0.5 \\
\hline 24 & 1 & -0.6 & 1 & -0.6 & 1 & -0.6 & 1 & -0.6 \\
\hline
\end{tabular}

${ }^{1}$ Group number of tariff plans that ensured maximum profit for the specified period 


\section{Conclusion}

During the research, we developed models of forming subscriber clusters (relying on the set of subscriber characteristics) and clustering tariff plans (relying on financial characteristics), using smart methods of data analysis. In contrast with other approaches, the set of subscriber characteristics includes only financial characteristics of subscribers' consumption and does not take into account socio-demographic characteristics of a company's clients.

Relying on the CLV characteristic, we discovered a relationship between clusters of subscriber consumption and tariff plans groups. As a result, we have proposed an approach to form- ing and estimating a tariff plan which provides the maximum value of CLV. The approach is based on subscriber profiles and investor preferences. We also have developed an IT tool (a Windows application written on $\mathrm{C} \#$ language) for assessing identified preferences of subscribers and investors of telecommunications companies while forming new tariff plans.

A proposed model for developing new and assessing existing tariff plans of a telecommunications company is based on the synthesis of a neural network and a genetic algorithm. The model was approved on a sample of $2,356,735$ observations covering the period from 1 January 2011 to 31 December 2014.

\section{References}

1. TMT Consulting (2018) Rossiyskiy rynok telekommunikatsiy: predvaritel'nye itogi 2017 goda [Russian telecom market: Preliminary results of 2017]. Available at: http://tmt-consulting.ru/wpcontent/uploads/2017/12/\%D0\%A2\%D0\%9C\%D0\%A2-\%D1\%82\%D0\%B5\%D0\%BB\%D0\%B5\%D0 $\%$ BA\%D0\%BE\%D0\%BC-20171.pdf (accessed 15 January 2018) (in Russian).

2. Kuzovkova T.A., Timoshenko L.S. (2009) Analiz i prognozirovanie razvitiya infokommunikatsiy [Analysis and forecasting of info-communications development]. Moscow: Hot Line - Telecom (in Russian).

3. Bogdanova T.K., Neklyudov D.Yu. (2016) Improvement of a telecommunications company tariff policy taking into account subscribers' preferences. Business Informatics, no. 2 (36), pp. 7-15.

4. Aivazyan S.A., Mhitaryan V.S. (1998) Prikladnaya statistika i osnovy ekonometriki [Applied statistics and fundamentals of econometrics]. Moscow: UNITY (in Russian).

5. Ershov E.B. (2008) Vybor regressii, maksimiziruyushchey nesmeshchennuyu otsenku koeffitsienta determinatsii [Selecting regression maximizing unbiased estimate of coefficient of determination]. Applied Econometrics, vol. 12, no. 4, pp. 71-83 (in Russian).

6. Kryshtanovsky A.O. (2000) Ogranicheniya metoda regressionnogo analiza [Limitations of regression analysis method]. Sociology: Methodology, Methods, Mathematical Modeling, no. 12, pp. 96-112 (in Russian).

7. Berger P.D., Nasr N.I. (1998) Customer lifetime value: Marketing models and applications. Journal of Interactive Marketing, vol. 12, no. 1, pp. 17-30.

8. Andreeva A.V. (2012) Optimal'noe upravlenie klientskoy bazoy na osnove pokazatelya dolgosrochnoy stoimosti klienta [Optimal control of a company's customer base using the customer lifetime value parameter]. Business Informatics, no. 4 (22), pp. 61-68 (in Russian).

9. Osowski S. (2002) Neyronnye seti dlya obrabotki informatsii [Neural networks for information processing]. Moscow: Finance and Statistics (in Russian).

10. Haykin S. (2006) Neyronnye seti: polnyy kurs [Neural networks: A comprehensive foundation]. Moscow: Williams (in Russian).

11. Kureychik V.V., Kureychik V.M., Rodzin S.I. (2012) Teoriya evolyutsionnykh vychisleniy [Theory of evolutionary computations]. Moscow: Fizmathlit (in Russian).

12. Kohonen T. (2008) Samoorganizuyushchiesya karty [Self-organizing maps]. Moscow: BINOM. Laboratory of Knowledge (in Russian). 